\title{
Conhecimento, ensino da administração e mudança transfor- madora: uma visão crítica
}

\author{
Knowledge, teaching of administration and transforming change: a critical view
}

\author{
Sergio Proença Leitão* \\ Luiz Carlos Gesualdi Junior**
}

\begin{abstract}
Resumo
As evidências demonstram que a crise socioambiental que afeta o planeta não pode ser resolvida por mudanças do tipo adaptativo. Ele requer mudanças na forma como conhecemos o mundo. Este artigo discute alguns problemas e possibilidades dos cursos de administração virem a induzir processos de mudança transformadora nas organizações, com repercussão na qualidade da vida associada.
\end{abstract}

Palavras-chave: mudança adaptativa; mudança transformadora; conhecimento; estrutura sociocognitiva.

\begin{abstract}
Evidences show that the socioenvironmental crisis that affects the planet can't be solved by adaptive changes. It demands changes in the way we know the world. This article discusses some problems and also possibilities of business administration courses to engage in a process of transforming changes with repercussions to the quality of the associated life.
\end{abstract}

Keywords: adaptive change; transforming change; knowledge; social cognitive structure.

\section{Discutir a mudança}

Pode ser redundante repetir que mudanças de caráter adaptativo - o sentido mais comum do termo mudança conduzidas pelo conjunto das instituições sociais e, em particular, pelas empresas produtoras, têm se mostrado insuficientes para solucionar, ou minimizar, a crise socioambiental que afeta o planeta. No entanto, pode ser oportuno reafirmar que, apesar de suas diversas facetas, o fato gerador dessa crise está na forma como conhecemos o mundo, no significado que damos às coisas que nos cercam.

Na realidade, os problemas já estão postos no noticiário dos jornais. Os que mais assustam são as múltiplas e mais contundentes formas de violência à pessoa, a constatação de que mais da metade de nossos ecossistemas estão ameaçados e a crescente concentração de renda. Preocupantes prognósticos feitos por cientistas de diversos países apontam para o agravamento da crise ambiental nos próximos 40 anos, com repercussão na vida associada.

McKinney (1997, p.17) observa que até há pouco tempo o acúmulo de omissões e erros cometidos na resolução de problemas ainda não havia atingido proporções que chamassem atenção. Agora, no entanto, a civilização humana não poderá sobreviver sem resolver isso, o que requer mudanças transformadoras na sociedade, nas organizações e, fundamentalmente, nos indivíduos.

\footnotetext{
* Professor-associado do IAG, PUC-Rio, Instituto de Administração e Gerência. Doutor em Educação pela UFRJ. Endereço: Rua Marquês de São Vicente 225, Gávea, Rio de Janeiro,/RJ - Brasil - CEP: 22453-900. E-mail: proença@iag.puc-rio.br.

** Professor adjunto do IAG, PUC-Rio. Doutorando em Administração pela PUC-Rio. Endereço: Rua Marquês de São Vicente 225, Gávea, Rio de Janeiro/RJ - Brasil - CEP: 22453-900. E-mail. Icgesualdi@ig.com.br.

Artigo recebido em janeiro de 2006 e aceito para publicação em fevereiro de 2006.
} 
As organizações produtoras, públicas e privadas, têm considerável responsabilidade, tanto pela poluição ambiental e pelo aquecimento do planeta, quanto pelo sofrimento humano causado pela concentração de renda, pela pobreza, pelo desemprego crescente ou pela qualidade das relações de trabalho. Problemas cuja solução não pode ser atribuída às políticas públicas, à Igreja ou às organizações não-governamentais, como alega o pensamento conservador. Nessa imensa rede de relações que caracteriza a vida associada, todos são responsáveis, até porque essa é uma crise do conhecimento sobre nós mesmos.

Em tal contexto, a mudança organizacional de natureza transformadora - também chamada radical ou de segunda ordem - torna-se um tema prioritário, se entendida como um processo capaz de mudar a visão dominante de mundo e a ideologia que a naturaliza (LEITÃO e ROUSSEAU, 2004). Cabe igualmente discutir o potencial dos cursos de administração para promoverem uma necessária e urgente mudança de mentalidade que começaria por seus próprios professores-pesquisadores e atingiria o sentir/pensar e o agir de alunos e empresários.

O processo de mudança nas organizações sociais, incluindo a academia, vem adotando uma visão de mundo predominantemente funcionalista. É um paradigma de ordem - nos termos do conhecido modelo de Burrel e Morgan ( 1982) e da sociologia de Merton -, porque é uma visão voltada para a manutenção do conjunto social da qual faz parte e que é incapaz de discutir o poder (MOTTA, 1986, p.100). Só pode aceitar ajustes ou adaptações à ordem estabelecida: mudanças à maneira do nobre Lampedusa, em $\mathrm{O}$ leopardo, à época da revolta de Garibaldi.

Esse paradigma é sustentado por uma ideologia produtivista, centrada no mercado e avalizada pela ciência positivista É um tipo de estrutura sociocognitiva, com seu conjunto de significados, desaparelhada para a autocrítica severa da atual forma de organizar o pensar e o fazer do sistema produtivo, que apóia, em todas as suas implicações sociais, um sistema altamente criativo, mas também dotado de forte destrutividade.

Lemkov (1990, p. 369) é um dos autores que afirmam que a educação pode mudar o atual paradigma e levar as novas gerações à uma compreensão mais abrangente da vida, corrigindo as origens daquela destrutividade e da concordatária ética do mundo dos negócios e da política; em suma, levar a um capitalismo transformado. Diz ela que a educação de hoje reflete a parcialidade reducionista e utilitarista da cultura dominante e que os jovens precisam aprender a relacionar vida pessoal com bem-estar social. O problema é que paradigmas (estruturas sociocognitivas) agem sobre a formação de conceitos e sobre as práticas, as políticas e as normas educacionais (EISNER, 1990, p.89). Trata-se, então, de voltar a educação contra quem a molda e delimita.

Em nível teórico se poderia começar pela questão conceitual que relaciona mudança e aprendizagem a conhecimento, uma vez que esses conceitos têm um vínculo ontológico, geralmente ignorado (LEITÃ̃ e ROUSSEAU, 2004), dificultando a compreensão da complexidade do mudar. Em termos gerais, não compreender as inter-relações existentes nos fenômenos humanos e sociais, e destes com os biológicos e com outros fenômenos, é uma das graves deficiências da educação modernista, a qual adota uma visão simples e linear da vida associada (MORIN, 2003, p.175).

Nesse sentido, a falta de uma visão integrativa acaba por omitir dimensões importantes como, por exemplo, a dimensão político-ideológica do conhecimento. A universidade pode ser vista, então, como um aparelho de Estado (MOTTA, 1986, p.102), um instrumento de dominação (BENSON, 1977), reprodutora dos interesses e da visão das classes dominantes, o que pode gerar fortes obstáculos a qualquer visão que contrarie seus interesses e sua postura ideológica. Tal dominação impõe o tipo de reforma que a universidade é capaz de aceitar, com reflexos numa pedagogia que ensina "o que" pensar e não "o como" pensar, com implicações profundas para a evolução do conhecimento acadêmico e a natureza da criatividade exercida. Esta acaba por se desenvolver da natural relação interativa entre ciência e técnica, mas de forma fortemente instrumental, sem a possibilidade de cortes epistêmicos transformadores da estrutura cognitiva dominante. Uma ciência que se realiza nos limites cognitivos da estrutura social dominante, com baixa capacidade para se auto-avaliar quanto a seus fins.

Nessa linha de discussão, este artigo aborda alguns problemas e possibilidades quanto ao ensino da gestão ser capaz de induzir uma mudança no paradigma e na ideologia dominantes, imprimindo nova orientação ao ensino 
e à pesquisa, com repercussão na qualidade de vida associada. Tomando como referência o caso brasileiro, este texto examina a área humano-social e o ensino de administração, pois as organizações produtoras, públicas ou privadas, têm poder para conduzir processos de mudança social, uma vez que são grandes disseminadoras do paradigma e da ideologia dominantes, particularmente, num mundo onde o Estado vem cedendo espaço ao poder das grandes corporações e do mercado.

\section{A questão do conhecimento no ensino universitário}

A arrancada do Iluminismo, liberto da censura teológica, possibilitou um substancial avanço das ciências: as maravilhas que as classes favorecidas melhor conhecem. Todavia, foi deixada marginal ao pensamento científico, a visão de complexidade que, depois da proposição de Gaston Bachelar, viria a ter inserção na universidade nos idos do século XX, com a cibernética e a teoria de sistemas. Só, agora, a complexidade é reconhecida como parte da problemática geral do conhecimento científico (MORIN, 2003, p.175).

A abordagem epistêmica simples pode ser considerada a raiz da atual crise de conhecimento, com seus pressupostos de dominação da natureza - origem do problema ambiental - ligada ao absoluto domínio do pensar instrumental, de natureza amoral e acrítica. Estamos falando das raízes cognitivas da crise do mundo atual; crise de solução complexa, inclusive, porque, como diz o biólogo e filósofo Humberto Maturana (2001, p.51), "todo sistema racional se baseia em premissas fundamentais aceitas a priori". Essas premissas se formam no nosso processo de socialização, incluindo aí a educação formal, o que nos leva a ver o mundo conforme fomos educados para vê-lo. A aceitação dessas premissas pertence ao domínio da emoção e não ao domínio da razão. Também por isso nosso raciocinar tem base emocional.

As neurociências, e a neurofisiologia, em particular, ciência base da Teoria dos Sistemas Vivos, de Humberto Maturana e Francisco Varela, e esta, da biologia cognitiva, vieram demonstrar que não podemos pensar sem sentir, que cognitivo e afetivo operam simultaneamente. Juntaram o que o cartesianismo havia filosoficamente separado, mas que ainda hoje é aceito como pressuposto da metodologia positivista.

Varela e Shear (2002, p.4) dizem que um observador independente acessar diretamente um fenômeno corresponderia a amputar o ser humano, lembrando que a experiência das práticas humanas é o ponto privilegiado para entender a mudança. Neurocientistas como Damásio, Caciopo, LeDoux, Gardner, Block, Tice, Sillman e outros confirmam essa forma do cérebro humano operar e reforçam a idéia de uma razão complexa, dotada de uma zona obscura, irracionalizável e incerta (MORIN, 2003, p.168). De outra ótica: não existe dicotomia entre valores e fatos (RAMOS, 1981, p.37).

Essa revelação tem fortes implicações quando se lida com a mudança no mundo humano-social. São implicações que levam a fortes resistências nas transformações em nossa estrutura cognitiva, pois mexem com o inconsciente e com o emocional. Behncke (1995, p.18) lembra que o pensamento modernista pressupõe que o professor-pesquisador pode se isolar de um fenômeno para explicá-lo, quando só podemos conhecer o conhecimento humano (experiências e percepções) a partir dele mesmo. Esta é uma ruptura importante com a visão positivista dominante, pois "isso é a expressão de nossa existência em um domínio de conhecimento no qual o conteúdo do conhecimento é o próprio conhecimento.” (BEHNCKE, 1995, p.19).

A biologia cognitiva da escola de Santiago coloca essa questão como o coração do problema do conhecimento. Isso tem total implicação quando se pensa em mudanças transformadoras que afetam paradigmas e as estruturas sociais cognitivas dominantes que, por sua vez, incorporam nossas premissas, pressupostos de conhecimento, valores e crenças (LEITÃO e ROUSSEAU, 2004).

A postura epistêmica dominante - relação agressiva com a natureza e intensa instrumentalização da vida - é hoje a questão central para uma mudança que leve ao aumento do bem-estar, consolidação da cidadania e mais justiça social, dando sustentabilidade à vida coletiva, num planeta com prazo para extinção da água potável. O problema está, então, em transformar a visão trazida pelo paradigma social dominante, com sua rede de significados; ou seja, transformar a nossa percepção de como deve ser a vida associada e, em particular, a vida orga- 
nizacional. Contudo, a ruptura com um paradigma dominante, necessária de tempos em tempos para corrigir a eficácia relativa das mudanças adaptativas, só é possível quando temos livre acesso a paradigmas alternativos, a outras estruturas cognitivas, paradigmas combinados (WOODMAN, 1989) ou a uma visão metaparadigmática (GIOIA e PITRE, 1990). Isso exige maior grau de liberdade no ensino e na pesquisa, que permita um pensar crítico-comparativo, o que a universidade como um todo, e os cursos de administração em particular, têm dificultado, ante a coalizão de interesses estabelecida entre as elites no poder e os profissionais do saber, manifesta nos currículos e nos modelos mentais desses professores-pesquisadores. Nesse sentido, a crítica antipositivista tem afirmado que todas as visões paradigmáticas são visões limitadas daquilo que chamamos realidade, rejeitando a possibilidade de um imperialismo do saber. Essa crítica, contudo, permanece contida, praticamente limitada a um pequeno grupo dentro da universidade. Nas escolas de gestão - que predominantemente seguem o modelo curricular norte-americano, o qual não abre alternativas (EISNER, 1990, p. 88), levando os alunos a aceitar o que é comum (a main stream) -, ainda é difícil adotar leituras com visões provenientes de epistemologias críticas como o desconstrutivismo, a teoria crítica, a fenomenologia, ou mesmo a emergente biologia do conhecimento, esta bem mais apta a lidar com a natureza humana do que o sistemismo da biologia de Bertalanffy. Elas têm sido mantidas à certa distância nos cursos de pós-graduação em administração, onde é priorizado o ensino do que é ferramental.

Não se nega aqui as muitas contribuições críticas no âmbito dos estudos organizacionais, nas últimas três décadas. O que se nega é que elas tenham surtido um efeito expressivo sobre a prática e o ensino de gestão, no que diz respeito à sua capacidade de transformação do meio empresarial. Além do que, muitas não propunham transformações, mas reformas. A resistência a essas perspectivas tem sido mais forte que seu poder de implantação. E se assim não fosse teria sido quebrada a hegemonia do positivismo funcionalista, ou de uma política cognitiva centrada no mercado, no dizer de Guerreiro Ramos (1981, p. 86). Estaríamos, pelo menos, vivendo nas salas de aula um amplo debate sobre as correntes alternativas ao pensar e agir na gestão, com mais espaço para elas nas disciplinas ministradas. Na realidade, autores críticos como Guerreiro Ramos e Prestes Motta permanecem à margem da main stream. Da mesma forma é negado espaço aos saberes da filosofia, da arte e da espiritualidade, embora sejam necessárias à compreensão do problema humano e à capacidade analítica da gestão. A ciência e sua derivada, a técnica, permanecem como únicas fontes confiáveis à verdade.

A falta de consciência do conhecimento que se tem, ou a condição considerada "natural" daquele conhecimento - resultado do trabalho ideológico dos donos do saber - é um mecanismo de perpetuação da visão dominante. Vistos de uma perspectiva epistêmica, os cursos de administração não são um centro de diversidade. McKinney (1997, p.19) lembra que pessoas com visões de mundo semelhantes tendem a se agrupar em comunidades que reforçam suas diferenças e estabelecem fronteiras entre os vários subgrupos. Se a diversidade de perspectivas for ignorada, ou defensivamente combatida, cada grupo continuará a defender sua continuidade, a permanência e a estabilidade do sistema. $\mathrm{Na}$ administração, temos um grupo nitidamente majoritário que detém poder sobre o ensino e a pesquisa. Por essa ótica está implícito que o conhecimento é o grande gerador de problemas, que ele forma discursos que estruturam o mundo, mas que também é a fonte de soluções. Na realidade, toda forma de vida associada pode ser compreendida e explicada como um processo afetivo-cognitivo que constitui fenômeno associado à consciência humana e também ao inconsciente (VARELA e SHEAR, 2002; VARELA, THOMPSON e ROSCH, 1993; GUSTAVSSON, 2001).

A máxima da biologia cognitiva de que vida é igual a conhecimento deixa no âmbito do conhecimento o locus onde os problemas têm de ser resolvidos, para que o equilíbrio vital seja restabelecido. Contudo, entende-se que esse conhecimento integra razão e emoção, aspecto este com que o ensino e a prática da gestão não têm sabido lidar, e que explica o apego dos professores-pesquisadores às suas posturas epistêmicas, já que o racionalismo é a razão de ser de seu trabalho. As propostas que visam mudar, de forma mais profunda, o que se ensina, têm sido neutralizadas pela negação de seu status ontológico (ALEE, 2002). Vai-se contra a natureza do fenômeno, com apoio na natureza do conhecimento adotado.

A dimensão política do conhecimento na universidade e em seus cursos de gestão se tornou problemática há muito tempo, em face dos seus vínculos com os donos do poder diretamente encastelados no Estado, incluindo os grandes detentores dos meios de produção. Bordieu e Passeron (1975) já haviam denunciado o caráter repro- 
dutivista da educação e como o poder das elites afeta não só as possibilidades de mudança nesse meio como a forma pela qual se a conhece.

$\mathrm{Na}$ academia ocorre uma relação circular entre o poder do conhecimento e o poder da administração acadêmica com capacidade para reprimir iniciativas transformadoras. Esse poder se manifesta na formação discursiva, num conjunto de distinções lingüísticas, nas formas de raciocínio e nas práticas que organizam aquela instituição, produzindo formas particulares de sujeito (ALVESSON e DEETZ, 1999, p.227). Existe aí uma manipulação cognitiva, embora o exercício do poder exija liberdade, pois formas autoritárias de organização, onde docentes e administradores vivem papéis contraditórios de cidadão livre e de cidadão robotizado, tornam-se campo fértil àquele tipo de manipulação.

Ao longo do tempo, a relação da universidade com o conhecimento tornou-se ambígua. O seu lidar com o saber instrumental e com o saber substantivo - que é moral e crítico em seus propósitos, mais diretamente vinculado ao nosso emocional - tornou impreciso o papel libertador/colonizador do conhecimento. A atual forma etnocentrista de globalização, identificada pela americanização da cultura (SZTOMPKA, 1998, p.162), parece reforçar sua função colonizadora, particularmente, no ensino da gestão.

Em sua evolução, a universidade acabou por se consolidar como uma organização corporativa, instituição de permissão ao exercício profissional através da concessão de diplomas reconhecidos pelos órgãos de classe e governos. As críticas à universidade denunciam não apenas sua incapacidade para se transformar e transformar a sociedade onde opera, mas também sua lenta capacidade para se ajustar às mudanças de comportamento e dos valores sociais. No campo da gestão, é vista como incapaz de acompanhar o ritmo inovador das empresas. Por outro lado, descobertas no âmbito das ciências de ponta, com alto grau de inovação no conhecimento científico, como ocorrem freqüentemente na física e na biologia, custam a chegar, quando chegam, às disciplinas da área humano-social. É como se o homem fosse apenas um ser antropossocial e não bioantropossocial, como diria Morin (2003, p.138). Paróquias, castas e egos inflados travam o desenvolvimento de visões multidisciplinares e tornam a integração interdepartamental uma realidade ainda distante. O mesmo ocorre nos cursos de administração, entre suas áreas de especialização. Essas são críticas conhecidas, o que não se conhece tão bem é o porquê da dificuldade para mudar, como superar as fontes de inércia.

Modernismo, mecanicismo, reducionismo, instrumentalização da vida, quantitativismo, produtivismo e adaptação são as palavras-chave do conhecimento dominante, muito explícitas em seus cursos de gestão. Esse conjunto de posturas cognitivas é insuficiente para a compreensão do mundo humano-social e propicia distorções no seu conhecimento, gerando e agravando a crise socioambiental.

Uma mudança transformadora requer a ruptura com esse paradigma; requer uma mudança "da" estrutura cognitiva e não "na" estrutura cognitiva dominante que orienta todo o ensino superior. Tal transformação requer um aprendizado de segunda ordem (VON FOESTER, 1996, p.59), segundo o conceito do biólogo Gregory Bateson, encontrado nos textos de Chris Argyris, e Peter Senge. Aprendizado que revê premissas, pressupostos e valores na reconstrução de uma nova percepção do que seja criar ou disseminar conhecimento. Esse, no entanto, está longe de ser o aprendizado de alunos e professores nos cursos de gestão.

Na realidade, aprender é um ato de permanente reconstrução num contexto de interações sociais, que implica mudança de um para outro estado cognitivo. Embora em toda sociedade exista um estrutura de significados preexistente ao indivíduo que nela ingressa, condicionante daquilo que ele aprende e como aprende, ao mesmo tempo ela lhe dá condições de desconstrução e reconstrução criativa (DEMO, 2000, p.101). Uma mudança transformadora irá exigir o desenvolvimento dessa forma de aprendizado, ao favorecer a crítica do conhecido a partir de novas visões paradigmáticas. Será preciso reconhecer, como prega a escola de Santiago, a natureza circular do conhecimento humano e do fenômeno tautológico, que impedem a explicação do universo de experiências e percepções do ser humano, a partir de uma perspectiva independente desse mesmo universo. Como já foi dito, só podemos conhecer o conhecimento a partir dele mesmo.

Por outro lado, a especialização do conhecimento encontrou na departamentalização uma exacerbação equivocada que aprofundou o fosso entre as disciplinas e os grandes campos da ciência (DEMO, 2000, p.95). O objeto 
de profissionalização acabou sendo prejudicado, na medida em que limita a capacidade dos estudantes pensarem de modo integrativo para enfrentar os novos desafios, cuja importância é, geralmente, proporcional ao ambiente interdisciplinar (DERRIDA, 1991).

Embora setores da academia estejam preocupados com esse tipo de mudança, ela é menos perceptível no caso dos cursos de administração. Aqui, a capacidade de discernir e avaliar os valores mais profundos das coisas ensinadas permanece bloqueada. Tais cursos se apresentam como um baluarte da resistência, encantados com a maneira management de ser.

\section{Ensino de administração e mudança}

Não é por acaso que a formação em administração vem sendo criticada pela sua alta especialização, rigidez curricular, falta de desenvolvimento de uma consciência crítica, quantitativismo exacerbado, economicismo, tecnicismo, ausência de consciência histórica e compreensão limitada do comportamento humano na empresa (CHANLAT, 1996, p. 24). Não existe a consciência crítica que favoreça a mudança, só a preocupação em apresentar o que está em voga nas grandes corporações. Benson já afirmava em 1977 que os estudos sociais não estavam suficientemente maduros para lidar com as mudanças transformadoras que a forma neoliberal de organizar a produção requer. Essa maturidade continua por vir.

O estudo de Armenakis e Bedeian (1999), revisando a literatura sobre mudança organizacional nos anos 1990, concluiu que nosso conhecimento sobre como as empresas surgem, desenvolvem-se, amadurecem e morrem ainda é limitado, e que a distância entre executivos chefes e demais membros das organizações ocasionam a rejeição de futuras transformações. De fato, não se percebem os limites impostos pela visão monoparadigmática sobre ampla gama de problemas organizacionais. A própria linguagem criada nas empresas - um sistema de descrição, explicação e interpretação do mundo baseado em categorias da gestão, chamado por Chanlat (2000, p.17) de "managerialismo" - constitui fator alienante para a pessoa.

Os professores de administração, majoritariamente, não têm consciência do paradigma que os orienta. Como a reprodução é a natureza da estrutura sociocognitiva hegemônica, a falta de consciência sobre a natureza do conhecimento que se tem realimenta o círculo vicioso professor/aluno/futuro professor. O modo como se ensina é como se aprende, até porque todo conhecimento se funda no passado e é acumulativo, operando como um centro que influencia o pensar de todas as coisas (KRISHNMURTI, 1999, p.20). Essa falta de consciência é um grande obstáculo à mudança. Isso tem implicações tanto para a compreensão da mudança como para seu ensino. Ao seguir um paradigma reducionista, como o funcionalismo, e uma ciência da simplicidade, assume-se uma visão estática e fragmentada do fenômeno, separando conhecimento, aprendizagem e mudança como áreas independentes de gestão. Ensina-se gestão do conhecimento, quando o conhecimento é que gere toda a vida administrativa. Não se vê o conhecimento que orienta o administrador que gere o conhecimento; um viés que tem implicações para que se tenha consciência do que é ensinado.

Em linhas gerais, ensina-se a solução de problemas quando a falta de uma visão complexa não permite compreender como surgem os problemas. Dessa maneira, nossa capacidade para alimentar e produzir problemas pode se tornar tão significativa como a de resolvê-los, num tipo de cultura que valoriza mais o fazer do que o pensar.

Não estar consciente da natureza do conhecimento que se tem impede o questionamento dos pressupostos de conhecimento das teorias dominantes. As chamadas escolas de negócios levam essa questão ao extremo, desinteressadas que estão de qualquer visão crítica do ensino/aprendizagem; são instrucionistas e se dedicam ao ensino do instrumental. As business schools, como, por vezes, se autodenominam, são culturalmente americanizadas nos currículos, nas leituras, tanto quanto na terminologia, o que torna impraticável falar de um ensino brasileiro da gestão. Tais escolas apenas reproduzem a corrente principal, despreocupadas com as implicações mais profundas do conhecimento que transmitem. Estão orientadas por uma perspectiva centrada no mercado, como se esta fosse a única dimensão da vida a ser transmitida aos futuros gerentes; como se a motivação econômica fosse o traço supremo da natureza humana (RAMOS, 1981, p.32). Morin (2003, p.112) diria que a na- 
tureza do conhecimento ensinado é técnica, fundamentando a simplificação e a manipulação generalizadas e inconscientes que são tomadas por racionalidade.

Essa visão especializante não poupa a pós-graduação em sentido estrito, onde os chamados mestrados acadêmicos adotam a mesma visão que os mestrados profissionais, com poucas diferenças curriculares. Quanto aos cursos de doutorado, criados para a formação básica de cientistas, eles se transformam em cursos profissionalizantes, também, por pressão discente e como conseqüência das condições gerais do mercado de trabalho, não apenas como resultado da visão dos professores. Nesse sentido, chama atenção a dificuldade dos doutorandos em pensarem como cientistas.

A mentalidade de "business" e a escassez de recursos acabam por desmotivar a pesquisa básica, geradora de novos conhecimentos, mas que não possibilita receitas imediatas. A pressão externa da Capes, como instituição avaliadora de desempenho institucional, é um dos fatores que têm impulsionado as publicações. No entanto, se o sistema recompensa a produtividade anual, isso pode não encorajar a produção de novas abordagens que envolvam risco de aceitação. É o que lembra Parker (1999, p.426), acrescentando que nem sempre as revistas estimulam trabalhos de qualidade e multidisciplinares, como seria desejável.

O exame dessas publicações mostra a preponderância de estudos que reproduzem acriticamente a visão dominante. Críticas "no" sistema são bem vindas, mas "do" sistema, nem tanto. Os textos mais aceitos, no campo da administração geral e dos recursos humanos, por exemplo, seguem a sociologia funcionalista americana. São raras as abordagens inter e transdisciplinares, necessárias para que se tenha uma visão complexa.

Artigos sobre organizações de grande potencial transformador, como as do projeto de economia de comunhão (BRANDALISE, 2003; PINTO, 2004) com fundamento na espiritualidade cristã, costumam suscitar rejeições, mesmo em revistas que dizem procurar artigos que desafiem o conhecimento e as práticas estabelecidas. Por outro lado, predominam os estudos sobre corporações, quando as pequenas empresas têm maior potencial transformador (LAND e JARMAN,1992, p. 225).

A dominância dessa reprodução acrítica do conhecimento, a aceitação do que adapta e a desconfiança em relação ao que transforma leva o ensino a um progresso míope, implicando a desumanização da gestão e do trato do ambiente natural, deixando o problema do bem-estar comum como algo alheio ao campo da administração. Questões fundamentais como o aumento da produtividade com desemprego crescente, a qualidade dos relacionamentos no trabalho, a dominação e a violência na gestão, a corrupção, a justiça social, a poluição, o transmaterialismo e outros temas diretamente associados à mudança nas práticas comportamentais na empresa permanecem extracurriculares. Como afirma Demo (2001, p.152),

é uma vida acadêmica ligada à transmissão copiada de conhecimento e parasitismo solene, que não agrega nada ao desafio do desenvolvimento humano, satisfazendo somente à pressão social por diplomas.

Essa visão é perfeitamente aplicável aos cursos de administração, onde não há espaço, ao menos, para uma disciplina integrativa que tenha como objeto da gestão o conjunto de saberes que favorecem a qualidade da vida associada. Uma disciplina que ligue esses cursos aos problemas socioambientais do mundo, para lançar um elemento de reflexão crítica no currículo. Em suma, na administração, ensina-se e aprende-se à velha maneira, embora com um discurso de modernidade, porque sua maneira de ver é modernista. Isso tem implicações não apenas quanto ao "que" se ensina, mas também em relação a "como" se ensina.

\section{A relação ensino/aprendizagem}

É um tema muito discutido por educadores que desejam conferir maior poder ao professor na elaboração de currículos, dando mais espaço à experiência, à sabedoria e à intuição, mas sem grandes progressos a registrar. A proposta reconhece a necessidade dos educadores empregarem formas de aprendizagem, pesquisando áreas de sua própria prática. Eisner (1990, p.96) chama isso de pesquisa-ação, conduzida para produzir um conhecimento do meio educacional a partir de contextos locais e agindo onde se pensa sobre o que se faz. 
Procura-se aí um contexto onde o educador deve ter auto-estima, mas sendo menos defensivo e menos egocêntrico, para possibilitar a emergência de idéias divergentes entre seus alunos, vistos como seres dotados de potencial renovador. É uma forma de educar que aceita as incertezas da vida e da ciência, inerente à complexidade do conhecimento, e que facilita o surgimento de novas perspectivas, permitindo aos consumidores do conhecimento ter algum espaço para participar da geração de significados.

$\mathrm{O}$ ambiente de uma organização de ensino requer qualidade nos relacionamentos interpessoais. A relação entre qualidade de relacionamento e aprendizagem é ponto pacífico para a pedagogia, para a psicologia cognitiva e para a biologia do conhecimento, as quais a consideram condição necessária ao aprender. Na realidade, o conceito de aprendizagem é em si mesmo relacional, pois está associado a todo o contexto da organização onde ela ocorre (BLEGER, 1989; KÄES, 1991). Ambientes autoritários, coercitivos, competitivos ou narcisísticos são hostis a esse fenômeno social, que constitui um ato de reconstrução situado em um contexto de interações sociais. Da sala de aula ao conjunto da universidade, o ambiente humano é vital ao ensinar/aprender, o que geralmente não é considerado nos processos de avaliação da academia.

Tal ambiente acadêmico deve pressupor também um tipo de relação entre professor e aluno que envolva mudanças pessoais, ao permitir que atitudes, crenças, valores, sentimentos e motivações venham à tona. A mudança do conhecer, em face dos condicionamentos do processo de socialização do indivíduo e da seletividade da percepção humana - com seus efeitos sobre os novos conhecimentos - requer autoconsciência e liberdade emocional. Isso implica outro tipo de formação para o educador, hoje preso exclusivamente a uma postura racionalista. Se não muda a pessoa, não muda a organização. Liberdade é aqui uma postura-chave, pois ela é a experiência de ser responsável pela sua responsabilidade (MATURANA e BUNNELL, 1998).

O ensino/aprendizagem atual, no campo da gestão de empresas, não é comumente visto como uma possibilidade de transformação pessoal; serve mais à acumulação de informações, camada sobre camada, com um centro desprovido de "substantividade", à maneira da cebola de Peer Gynt. Falta estímulo à reflexão e à crítica dos dogmas e dos modismos. Centrado nos limites do mercado, é um sistema educativo que inviabiliza o processo contínuo de mudança comportamental, através da mudança contínua na capacidade do sistema nervoso de sintetizar o ambiente, como lembra Demo (2001, p.185), baseado em Autopoiesis and cognition, de Maturana e Varela. Esses biólogos revelam que aprender não é acumular representações do meio ambiente.

Uma visão complexa do ensino/aprendizagem na universidade leva a relacionar coisas, transcender a cultura e discutir a sabedoria coletiva, num tipo de relação professor/aluno em que é reconhecido que cognitivo e afetivo não se separam. De fato, o estímulo ao equilíbrio nessa relação neurofisiológica (o racionalismo acadêmico expulsou o emocional do ensino e da pesquisa) confere autoconsciência e liberdade emocional, ampliando a capacidade do pensar/sentir. Ambientes que estimulam a ambição, o medo e a competição restringem a visão e a inteligência vitais para o mudar (MATURANA e BUNNELL, 1998).

A mudança comportamental no binômio professor/aluno, ao permitir maior autonomia aos seus participantes e expulsar o autoritarismo anticriativo, constitui condição básica para uma visão crítica da estrutura de poder e cognitiva vigentes. Nesse contexto, os sistemas de avaliação continuam sendo necessários para conferir não apenas eficiência e eficácia aos currículos, mas também efetividade - entendida como a capacidade de atender às necessidades de todo o pessoal acadêmico - e relevância - a capacidade da instituição atender às necessidades da comunidade onde atua.

Embora a questão da avaliação do desempenho da academia seja particularmente relevante, por um lado, ela ainda é pouco presente na literatura (SIMMONS, 2002); por outro, a própria academia, com seus vícios corporativistas, continua resistindo a se auto-avaliar, o que é uma postura antimudança. Naturalmente, o problema da auto-avaliação se insere na questão da autonomia para a universidade e de sua governança, dela decidir seu destino e conquistar maior influência sobre a vida coletiva. Essa também é uma questão ainda não resolvida. 


\section{Reflexões finais}

Neste artigo foi discutido, ainda que de forma não-exaustiva, se o ensino da gestão é capaz de transformar pessoas e organizações sociais, assumindo-se que esse é um processo complexo, envolvendo armadilhas cognitivas ainda não resolvidas. É de se admitir que os problemas são maiores do que as possibilidades, ante a força reprodutiva do sistema educacional e da ordem vigente.

Ainda que de uma perspectiva impressionista, pode-se suspeitar que não exista clara causalidade entre ensino e estudos organizacionais, que tratam da mudança transformadora com a experiência de empresas que passaram por esse tipo incomum de mudança. Desconhecemos estudos empíricos que comprovem tal relação.

É possível afirmar, por exemplo, que essa relação não existe no caso das empresas do Projeto de Economia de Comunhão (BRANDALISE, 2003; PINTO, 2004; GONÇALVES, 2005; LEITÃO e KURTZ, 2005). Essas empresas, em sua maioria de pequeno e médio porte, implantaram mudanças importantes na relação entre capital e trabalho e na distribuição da renda gerada. Romperam com a política cognitiva centrada no mercado, baseada essencialmente nos princípios dos Evangelhos e da Doutrina Social da Igreja para reinterpretar alguns princípios da economia e da prática administrativa. Nesse caso, existem micro e pequenos empresários que nunca tiveram contato com a literatura sobre mudança ou mesmo com cursos de administração. As bases teóricas desse projeto ainda estão por ser formuladas.

Na realidade, é pequena a produção de pesquisas sobre o tema "transformação". As técnicas de gestão que são conhecidas, principalmente, o planejamento estratégico, não discutem ou alteram princípios da economia de mercado. Também nos casos da economia solidária ou do movimento de responsabilidade social corporativa que, inclusive são, por vezes, de enquadramento problemático no conceito de mudança transformadora -, podemos atribuir influência àquela. Possuem dinâmica própria, muito presa a seus altos executivos e têm vínculos com a corrente humanista da administração, como no caso anterior do projeto de economia de comunhão.

A impressão que se tem é que das outras experiências empresariais, como algumas das descritas por Omar Aktouf em sua Administração renovada, a mudança vêm de fatores outros que não a influência do ensino acadêmico na transformação empresarial. Existem, inclusive, diferenças relevantes entre orientar para a transformação e orientar para a adaptação aos mercados; e os textos, ou os cursos, nem sempre fazem essa distinção. Ficase então na falta de maiores explicações sobre o que motiva empresários a mudanças daquela natureza. Este não tem sido o objetivo prioritário da pesquisa. O tema parece uma questão "acadêmica", em sentido pejorativo, desprovido de praticidade.

Em suma, desde a denúncia de Herbert Marcuse - em suas obras dos anos 1960 sobre o desenvolvimento de uma sociedade tecnológica, operando através do conhecimento instrumental como um sistema de dominação social -, ficou claro que é difícil qualquer esforço de emancipação, no sentido de mudar a ordem vigente, devido ao poder de cooptação que tem um sistema onde o poder é incorporado à maquina produtiva. A universidade e, particularmente, os cursos de administração, transformaram-se em instrumentos desse sistema de dominação (essencialmente cognitivo), a partir de uma visão neoliberal de como o mundo deve ser.

Maturana (2001, p.29), olhando de uma perspectiva filosófico-biológica, lembra que a educação faz da comunidade humana um mundo conservador - com efeitos de longa duração -, mas também que é possível repensar a forma como se educa. Para ele, em termos básicos, educar significa recuperar uma harmonia fundamental que não destrói, não explora e não pretende dominar o mundo natural, mas conhecê-lo na aceitação e respeito, para que o bem-estar humano se dê no bem-estar da natureza em que se vive. Para Maturana, fatores culturais têm alterado aquilo que é a natureza biológica do ser humano - com pesadas implicações para o nosso bem-estar e precisam ser mudados.

Esta poderia ser uma sabia postura para a tarefa do educador em administração, seja para ensinar as coisas úteis à vida, sem recair no utilitarismo, seja para ensinar as coisas pensadas inúteis pela ordem vigente, porque elas podem vir a se transformar em coisas extremamente úteis. 
O campo da gestão precisa aprofundar sua autocrítica e substituir os princípios da inteligibilidade da ciência clássica - que alimentam o paradigma da simplificação -, construindo um paradigma da complexidade. Este não determina a inteligibilidade das coisas, mas instiga o pesquisador a considerar a complexidade de todos os fenômenos estudados. Incita à multidimensionalidade, ao pluralismo cognitivo, às múltiplas inteligências da vida, como propõe Morin (2003, p.332). Este pensador libertário acredita que para enfrentarmos os dramáticos problemas do mundo atual, precisamos dar um grande salto civilizacional e histórico na direção do conhecimento complexo; numa transformação afetivo-cognitiva.

Como todo processo social, o conhecimento constitui um ciclo produtivo ininterrupto, onde seus produtos são necessários à produção daquilo que o produz. Contudo, esse ciclo pode ser rompido por uma aprendizagem não apenas reprodutiva, mas com alteração de qualidade, capaz de desconstruir o já construído, rever os pressupostos sobre os quais se conhece, a partir de novas visões de mundo que possibilitam o contraste, o conflito perceptivo necessário à reflexão. Uma aprendizagem que considere, inclusive, que a própria noção de paradigma (estrutura sociocognitiva) deve ser entendida de uma perspectiva complexa, que aceite ordem e desordem, objetivo e subjetivo, singularidade e multiplicidade (auto-organização e eco-organização) na vida coletiva. Se o problema é o conhecimento, a solução está no aprendizado de novas formas inter e transdisciplinares de conhecer, já que a "ciência normal" não provou ser a forma de conhecimento superior a todas as outras. A busca por maior contato com a realidade deve continuar, impondo rupturas ao domínio do pensamento conservador na gestão. Isso, no entanto, implica a práxis gerada por uma democracia libertária no âmbito das organizações que lidam com o conhecimento. Sem isso, o ensino da gestão e suas práticas, com todas as suas aparentes novidades, continuarão a ser novas versões de um velho saber.

Se o Estado detém o monopólio normativo do conhecimento, podemos supor que deverão ocorrer mudanças nas elites do poder e o afrouxamento da censura procustiana exercida pelos feudos do saber. O que se questiona é se isso pode ocorrer a partir de um ato volitivo profundamente ético, fruto da tomada de consciência da crise planetária e da ameaça à nossa e a todas as espécies. É possível que esse ato seja consequiência da pressão das elites intelectuais mais esclarecidas e da crescente manifestação dos oprimidos e dos movimentos sociais, gerando uma nova política cognitiva para romper a inércia. A crise está afetando também as classes mais favorecidas, e é possível que a nova ordem psicossocial, de grande insegurança, motive mudanças.

No entanto, parece provável que para os cursos de administração se transformarem em agentes de mudança de segunda ordem, terão que se dedicar mais ao conhecimento sobre o conhecimento que vem, historicamente, gerando os atuais problemas socioambientais. A universidade deveria assim se transformar numa organização que aprende a aprender, ensinando a lidar com a incerteza e as diferenças.

Contudo, são múltiplas e complexas as dificuldades para que isso venha a acontecer. Conforme afirma Huy (1999), em termos esquemáticos, tal tipo de mudança implicaria receptividade à idéia de transformação, mobilização na direção da mudança e aprendizagem coletiva e interativa na construção de novos significados. Os problemas decorrentes dessa dinâmica são facilmente imagináveis à luz do já exposto. E nos trazem à memória a afirmação de um professor, quando se discutia a concepção de um novo curso de doutorado em administração, de enfoque inteiramente inovador:

o que vocês propõem, vai exigir de nós um reaprendizado, uma revisão em nossos conhecimentos, envolvendo um esforço que a maioria de nós não está disposta a começar.

Motivações, pressupostos de conhecimento, crenças, ideologias profundamente arraigados, que são a base de nosso sentir/pensar, muito tem de ser revolvido.

O que se conclui quanto à questão de se os cursos de administração podem atualmente contribuir para a indução de mudanças transformadoras nas organizações produtoras é que ela ainda tem resposta negativa. Esses cursos continuam voltados para o ensino de como ganhar dinheiro através das técnicas de gestão.

Todavia, pode-se admitir, nos movimentos dialéticos da vida, indícios de mudanças que podem estar partindo do crescimento da corrente humanista na administração. Sua base original - na teoria crítica, no anarquismo e 
no existencialismo francês - parece estar incorporando contribuições do pensamento cristão e do pósmodernismo, estimuladores da reflexão no interior de movimentos sociais. É provável, também, que ela seja enriquecida por um maior conhecimento das condições biológicas humanas, trazido pela biologia cognitiva e pelo movimento da ecologia profunda. Possivelmente, estejam ocorrendo movimentos "conspiratórios" no interior da universidade, como dizia Marilyn Ferguson no best seller A conspiração aquariana. No entanto, movimentos revolucionários só se tornam conhecidos quando se rompe a ordem vigente, o que ainda não ocorreu.

O paradigma humanista tem explícita proposta de ruptura com o paradigma dominante e com a ideologia produtivista que o apóia. Está claramente engajado na transformação organizacional, social e ambiental, na transformação do atual operar do capitalismo. Seu crescimento é perceptível na literatura acadêmica e empresarial, e já começa a entrar nas salas de aula, em algumas disciplinas. Está também lançando novos temas na teoria organizacional e reformulando temas anteriormente assumidos pelo funcionalismo (LEITÃO e LAMEIRA, 2005).

Aqui está o mais provável caminho teórico nesse tipo de mudança, embora ela já venha se manifestando no meio empresarial, nos casos anteriormente citados. O que se observa nas empresas, que vêm adotando tal enfoque, é uma sensível melhora na qualidade das relações interpessoais e interorganizacionais, acompanhada de maior preocupação ambiental.

Ainda assim não se pode afirmar que a academia esteja na liderança do processo. É mais provável a existência de uma liderança empresarial do que a ocorrência de um paralelismo. Talvez, porque os empresários sejam mais sensíveis à vida associada, ou tenham a iniciativa e a capacidade de ação que o puro "conspirar" dos intelectuais da academia não permite.

No âmbito da administração acadêmica, para os cursos de gestão assumirem essa liderança, mudanças substantivas ainda precisam ocorrer. Devem começar pelo reconhecimento da vontade de mudar e pela concessão de mais espaço às mentes e às idéias transformadoras, tolhidas na atual estrutura de poder.

Sem maior diálogo entre as diferentes visões não se pode compreender os impasses em nosso sentir/pensar e chegar à ruptura necessária. O que não parece razoável é continuar acreditando que o atual paradigma que gerou progresso, mas também grandes impasses ao bem-estar comum da maioria da população mundial, seja capaz de resolvê-los. 


\section{Referências}

ALEE, V. The art and practice of being revolutionary. Journal of Knowledge Management, v.3, n.2, p.252-261, 2002.

ALVESSON, M.; DEETZ, S. Teoria critica e abordagens pós-modernas. In: CLEGG, HARDY; NORD (Org.). Handbook de Estudos Organizacionais. São Paulo: Atlas, 1999.

ARMENAKIS, A. A.; BEDEIAN, A. G. Organizational change: a review of theory and research in the 1990s. Journal of Management, v.25, n.3, p.293-315, 1999.

BEHNCKE, R. Ao pé da árvore. Prefácio. In: MATURANA H.; VARELA, F. A árvore do conhecimento. São Paulo: Editorial Psy, 1995.

BENSON, J. K. Organizations: a dialetical view. Administrative Science Quarterly, v.22, p.397-418, Mar. 1977.

BLEGER, J. Psicologia da conduta. 2.ed. Porto Alegre: Artes Médicas, 1989.

BORDIEU, P.;PASSERON, J. C. A reprodução: elementos para uma teoria do sistema de ensino. São Paulo: Francisco Alves, 1975.

BRANDALISE, L. A. A finalidade do lucro para as empresas de economia de comunhão. Tese (Doutorado) - Faculdade de Economia, Administração e Contabilidade, USP, set. 2003.

BURREL, G.; MORGAN, G. Sociological paradigms and organizational analysis: elements of sociology of corporate life. London: Heinemann, 1982.

CHANLAT, J.-F. 0 indivíduo na organização. Dimensões esquecidas. São Paulo: Atlas, v.1, 1996.

Ciências sociais e management. São Paulo: Atlas, 2000.

DEMO, P. Conhecer \& aprender. Sabedoria dos limites e desafios. São Paulo: Artmed, 2000.

Conhecimento moderno. Sobre ética e intervenção do conhecimento. Petrópolis: Vozes, 2001.

DERRIDA, J. Margens da filosofia. Campinas: Papirus, 1991.

EISNER, E. W. The meaning of alternative paradigms for practice. In: GABBY, E. (Ed.) The paradigm dialogue. Newbury Park, CA: Sage Publications, 1990 .

GIOIA, D. A.; PITRE, E. Multiparadigm perspectives on the theory building. Academy of Management Review, v.15, n.4, p.584-602, 1990.

GONÇALVES, H. H. O. A experiência dos pioneiros da economia de comunhão na liberdade no primeiro decênio (1991-2001) no Brasil: absurdo e graça da mudança de mentalidade do empresário. Tese (Doutorado) - Coppe, UFRJ, Rio de Janeiro, 2005.

GUSTAVSSON, B. Toward a transcendent epistemology of organizations: new foundations for organizational change. Journal of Organizational Change Management, v.14, p.352-378, 2001.

HUY, Q. N. Emotional capability, emotional intelligence and radical change. Academy of Management Review, v.24, n.I.2, Apr. 1999.

KÄES, R. A instituição e as instituições: estudos psicanalíticos. São Paulo: Casa do Psicólogo, 1991.

KRISHNMURTI, J. Sobre a aprendizagem e o conhecimento. São Paulo: Cultrix, 1999.

LAND, G.; JARMAN, B. Para além do ponto de ruptura. In. RAY, M.; RINZLER, A. (Org.). 0 novo paradigma nos negócios. São Paulo: Cultrix, 1992.

LEITÃO, S. P.; KURTZ, R. M. Relacionamentos interpessoais e aprendizagem na economia de comunhão: o caso Femaq. Revista de Administração Pública, v.27, n.4, jul./ago. 2005.

; LAMEIRA, V. J. Humanismo e mudança organizacional. Revista de Administração Pública, v.39, n.3, p.731-752, maio/jun. 2005. ; ROUSSEAU, K. Introdução à natureza da mudança transformadora nas organizações na perspectiva da biologia cognitiva. Revista de Administração Pública, v.38, n.2. mar./abr. 2004.

LEMKOV, A. F. 0 princípio da totalidade. São Paulo: Aquariana, 1990. 
MATURANA, H. Emoções e linguagem na educação e na política. Belo Horizonte: UFMG, 2001.

; BUNNELL, P. Biosphere, homosphere and robosphere: what has that to do with business? Society for Organizational Learning Member's Meeting. Mherst, MA, June 1998. Disponivel em: <http://www.solonline.org/res/wp/maturana/index.html>.

McKINNNEY, W. Alternatives realities. In: McKINNEY. Paths of change. London: Sage Publications, 1997.

MORIN, E. Ciência com consciência. Rio de Janeiro: Bertrand Brasil, 2003.

MOTTA, F. P. Teoria das organizações: evolução e crítica. São Paulo: Biblioteca Pioneira, 1986.

PARKER, B. Evolução e revolução: da internacionalização à globalização. In: CLEGG; HARD; NORD (Org.). Handbook de Estudos Organizacionais, São Paulo: Atlas, 1999. v.1.

PINTO, M. C. S. A economia de comunhão sob o olhar da teoria dos stakeholders. Tese (Doutorado) - Departamento de Administração da PUC-Rio, jun. 2004.

RAMOS A. G. A nova ciência das organizações. Rio de Janeiro: Editora FGV, 1981.

SIMMONS, J. An "expert witness" perspective on performance appraisal in universities and colleges. Employee Relations, v.24, n.1, p.86100, 2002.

SZTOMPKA, P. A sociologia da mudança social. Rio de Janeiro: Civilização Brasileira, 1998.

VARELA, F.; SHEAR, J. The view from within. First person approaches to the study of consciousness. USA Imprint Academic, 2002.

;THOMPSON, E.; ROSCH, E. The embodied mind: cognitive science and human experience. Massachusetts: Massachusetts Institute of Technology Press, 1993.

VON FOESTER, H. Visão e conhecimento: disfunções de segunda ordem. In: SCHINITIMAN, D. F. Novos paradigmas, cultura e subjetividade. Porto Alegre: Artes Médicas, 1996.

WOODMAN, R. W. Evaluation research on organizational change: arguments for a

'combined paradigm' approach. Research in Organizational Change and Development, v.3, p.161-180, 1989. 